\title{
Astronomical Control of the Hydroclimate During the Past 1.2 Million Years
}

\author{
Leonidas Brikiatis* \\ Unaffiliated, 17564, Palaeo Faliro, Greece \\ ${ }^{\star}$ Corresponding author: Leonidas Brikiatis, Ioannou Fix 5, 17564, Palaeo Faliro, Greece; E-mail: lb@aegeanman.com
}

Received: May 05, 2021; Accepted: May 12, 2021; Published: May 18, 2021

\begin{abstract}
Although extensively studied, the particular contribution of the Earth's orbital parameters to the intensity and periodicity of the Pleistocene glacialinterglacial cycles remains unresolved. Here, I approach the issue from the perspective of hydroclimatic variation by reconsidering the available palaeoclimatic records of the past 1.2 million years. Correlation of various direct and indirect hydroclimatic proxies consistently converges to highlight a hyetal spectrum of hydroclimatic intensity driven by quasi-22-kyr insolation oscillations due to eccentricity-modulated precession of the Earth's rotational axis. The only and striking exception occurs at $\sim 880 \mathrm{kyr}$, coinciding with the onset of the quasi-100-kyr glacial periodicity and the extremely cool and arid period known as the "900-kyr event". The high insolation prevailing during that period suggests that the climate anomaly was not orbitally forced but instead was due to a currently undefined feedback perturbation of the Earth's internal climate system. Furthermore, lower and higher hyetal periods seem to be closely related to glacial and interglacial cycles, respectively. The real mechanism of that relation is currently not well understood and might constitute a missing link coupling the Earth's orbital and climatic histories.
\end{abstract}

Keywords: Early-to-Middle pleistocene transition, Earth's orbital parameters, Glacial-interglacial cycles, glaciation, Hydroclimate, Pleistocene

\section{Introduction}

The onset of the current geologic period, the Quaternary [Holocene and Pleistocene; 2.58 million years (Myr) to present], was characterised by the intensification of Northern Hemisphere glaciation and variation in the intensity, shape, and duration of glacial-interglacial cycles [1]. During those cycles, relatively short interglacial periods with relatively warm climate and duration of a few thousand years were separated by colder periods lasting several tens of thousands of years. The reasons for that climatic variation have been a subject of study for almost two centuries and have been attributed to factors both internal and external to the climate system (ref. [2-4], and references therein). The astronomical hypothesis is one of the oldest explanations but was not formulated as a theory until 1941, when it presented by the Serbian geophysicist and astronomer Milutin Milanković [3]. The Milanković theory claims that the palaeoclimate was driven by perturbations of the Earth's orbit and rotational axis. That view was largely disputed until the mid-1970s, when critical climatic information was recovered by the Ocean Drilling Programs (ODP) that demonstrated that the pace of the climatic variation matched the variation of the Earth's orbital parameters [2]. More recent studies revealed, however, that the climate feedback on the Earth is more complicated than a simple linear system. For example, although the Milanković theory claims that obliquity-dominated oscillations in incoming solar radiation (insolation) at latitudes $>65^{\circ} \mathrm{N}$ are the main factor controlling glacial cycles, the Earth is currently going through an interglacial culmination, but the current insolation has the same magnitude as that during the glacial culmination that occurred about 18,000 years ago [5]. Similarly, although the Milanković theory predicts the occurrence of glacial cycles in accordance with the 41-kyr periodicity of the tilt of the Earth's axis (obliquity), which has a relatively large effect on insolation, most analyses of the last $\sim 900,000$ years of climatic history have concluded a quasi-100-kyr periodicity for glacial cycles, which is most compatible with the variation in the eccentricity of the Earth's orbit, a parameter with a relatively small effect on insolation $[2,6]$. The inability to demonstrate a linear relationship between the insolation variation and the intensified glacial-interglacial cycles of the last $\sim 900,000$ years (from the onset of the middle Pleistocene to today) has led some researchers to introduce a stochastic parameter into their models of the climate system [7], whereas others have concluded that we are currently unable to understand the real mechanism driving glaciation $[3,8]$. The relationship between the global climate cycles and the Earth's orbital parameters has been exhaustively investigated through palaeotemperature proxies. I took a different approach by exploring that relationship in terms of the variation in another important climatic factor, the hydroclimatic variation. To that end, I reconsidered the global palaeoclimatic record of the last 1,200,000 years in order to reconstruct the global trends in hydroclimatic intensity during the late Quaternary. The correlation of that variation with the oscillations of orbital parameters and palaeotemperature proxies allows further investigation of whether and how all those parameters are related to one another.

\section{Materials and Methods}

The global palaeoclimatic record of the last $1,200,000$ years was reconsidered to investigate whether there are direct and indirect palaeohydroclimatic proxies with satisfactory resolution and precise timescale that can reliably reconstruct the global trends in the variation of the late Quaternary hydroclimatic intensity (Figure 1). 


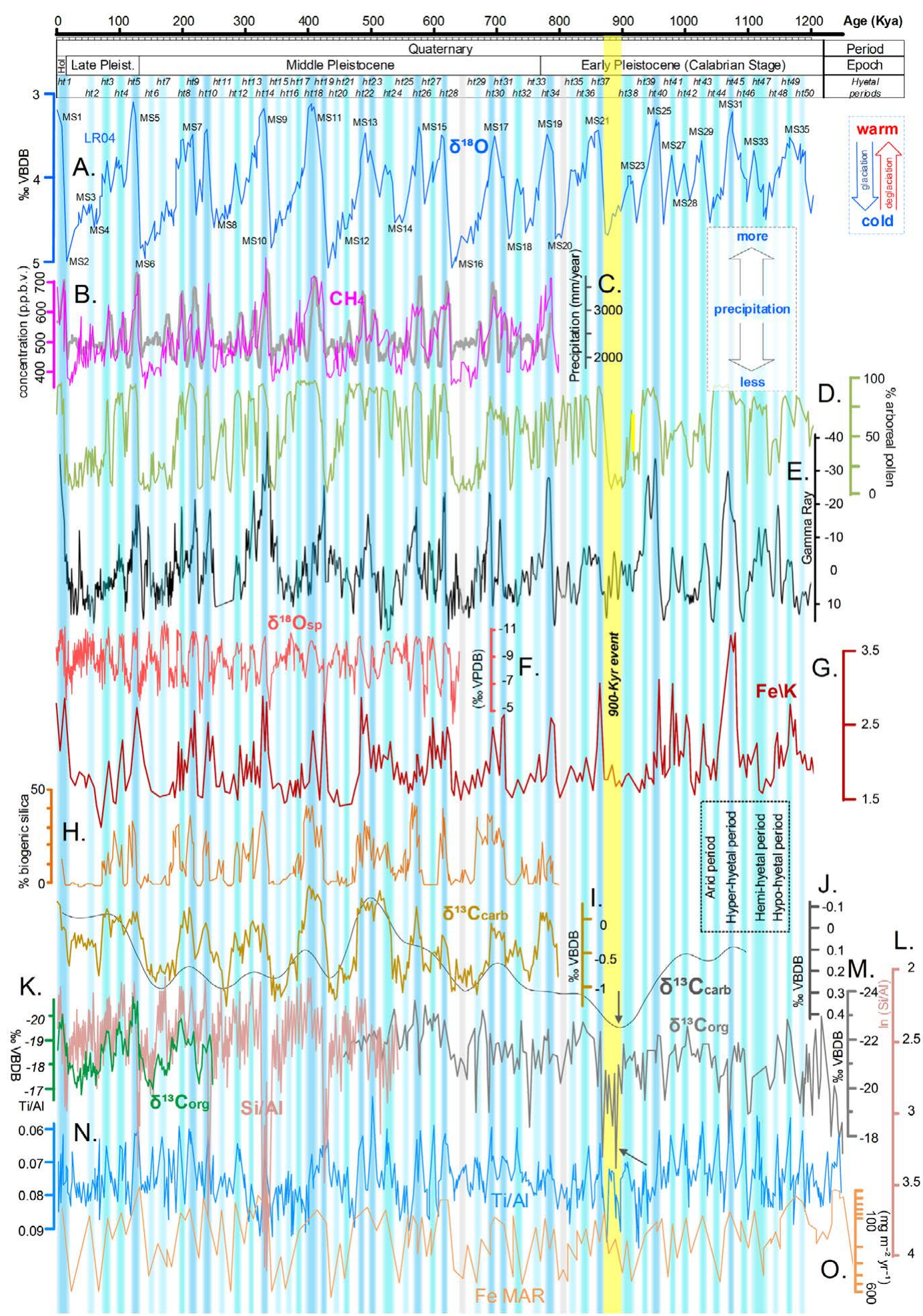

Figure 1: Correlation of palaeotemperature (A) and various direct and indirect hydroclimatic proxies of the last 1.2 million years (see the Materials and Methods). A) Stack of 57 globally distributed benthic $\delta^{18} \mathrm{O}$ records [6] (palaeotemperature proxy). MS=Marine Stage. B) Atmospheric methane record from the EPICA Dome C ice core, Antarctica [36]. C) LOVECLIM simulation of the annual mean precipitation amount for the Lake Ohrid [63]. D) Palynologic record, Tenagi Philipon, Greece [25]. E) Gamma ray series at ODP Site 1119, east of South Island, New Zealand [64]. F) Composite $\delta^{18}$ Osp from Chinese caves as a proxy of the Asian Monsoon [9]. G) Iron/potassium (Fe/K) ratio, IODP Site U1467, Maldives Archipelago [22]. H) Biogenic silica accumulation, Lake Baikal, Russia [29]. I) Stack of three Southern Ocean carbonate carbon isotope $\left(\delta^{13} \mathrm{C}_{\text {carb }}\right)$ records ODP 1090, ODP 1089, and GeoB1211 [65]. J) Stacked and smoothed carbonate carbon isotope $\left(\delta^{13} \mathrm{C}_{\text {carb }}\right)$ from benthic foraminifera of the global ocean [66]. K) Organic carbon isotope record $\left(\delta^{13} \mathrm{C}_{\text {org }}\right)$ of marine sediments including predominantly terrestrial material from Niger deep-sea fan (GeoB 4901), West Africa [18]. L) Log-ratio of silica to aluminium as a proxy of sediment opal content (ODP Site 658, subtropical North Atlantic [48]. M) Organic carbon isotope record $\left(\delta^{13} \mathrm{C}_{\text {org }}\right)$ of marine sediments including equivalently mixed material of terrestrial and marine photosynthesis, ODP Site 1077, Angola Basin [67]. N) Ti/Al ratio, ODP Sites 967 and 968, eastern Mediterranean [17]. O) Mass Accumulation Rate (MAR) of iron deposition, ODP Site 1090, Southern Ocean [30]. The vertical bars in different shades of blue form a hyetal spectrum highlighting periods of various hydroclimatic intensity. The green $\delta^{13} \mathrm{C}$ graph from the Niger deep-sea fan and the magenta loess $x f d$ record from China are superimposed on other graphs for comparison. Black arrows show the remarkable values of various proxies during the 900 -kyr event. 
The correlation of that variation with the oscillations of both orbital parameters and palaeotemperature proxies allows further investigation of whether and how all of those parameters are related to one another (Figure 2). The investigation considered not only direct and well-established proxies of hydroclimatic intensity but also other proxies that might be indirectly related through mechanisms that are not well understood (Figures 1, 3 and 4). Potential covariation of the latter with the direct hydroclimatic proxies is expected to either confirm their physical property as hydroclimatic proxies or to reveal information about the specific mechanism responsible for the observed

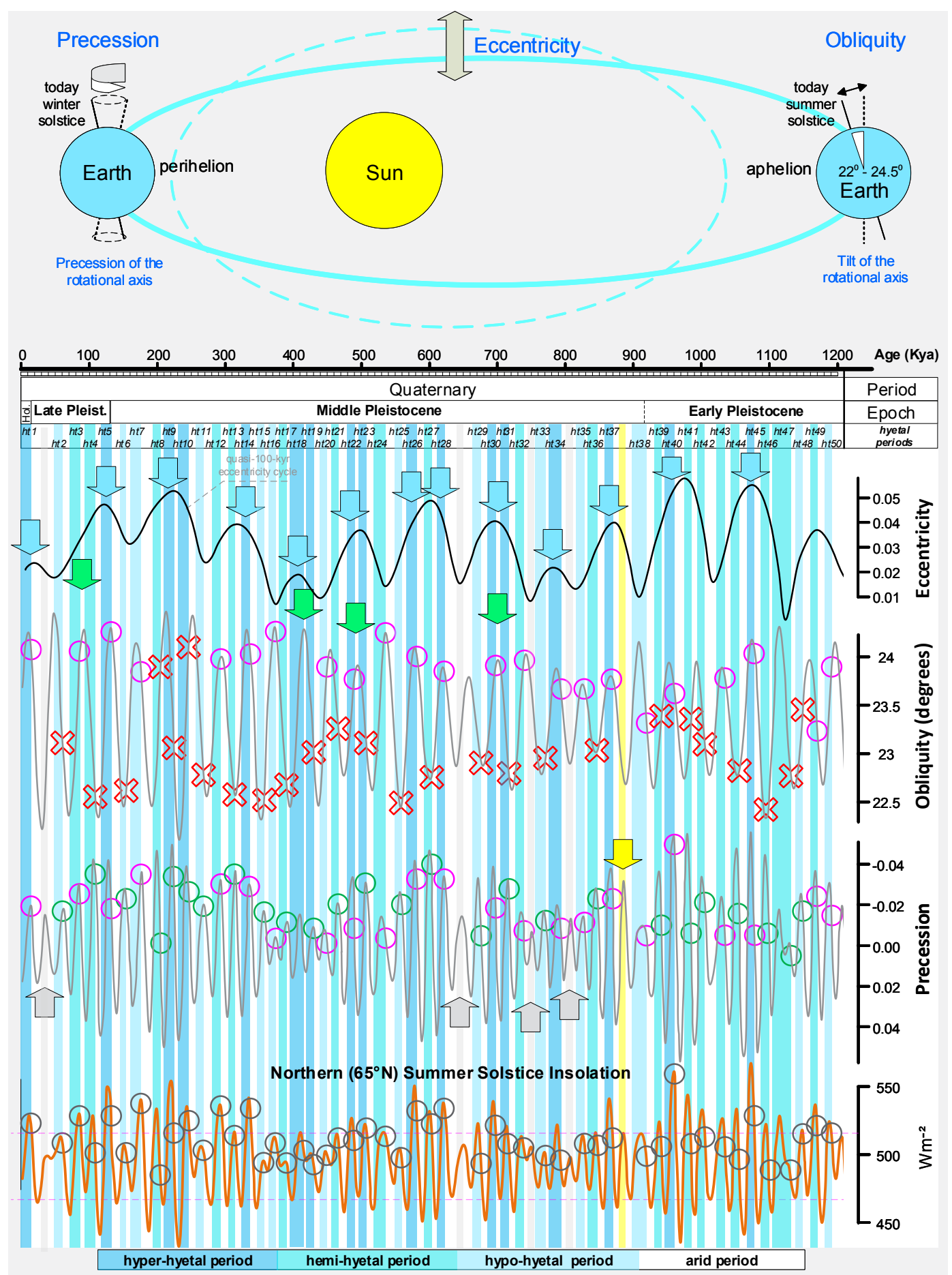

Figure 2: Correlation of the hyetal spectrum with the Earth's orbital parameters $[68,69]$. Blue arrows point out that hyper-hyetal periods always occur during the orbital periods of high eccentricity. Coloured circles indicate the coincidence of the onset of a hyetal period with either the climatic precession and/or the obliquity maxima: green circles indicate exclusive identity; magenta circles indicate coincidence with both orbital phenomena. Red X symbols indicate failures of either climatic precession or obliquity to explain the onset of a hyetal period, that is, whenever their oscillations coincide with decreasing rather than increasing solar insolation trends. The grey arrows note that precession minima correspond to hypo-hyetal and/or arid periods only during periods of eccentricity minima. To emphasise the precessional effect, hyetal cycles are correlated with the insolation oscillations at $65^{\circ} \mathrm{N}$ high latitude (bottom graph), which is an area mainly dominated by obliquity-dependent insolation. The horizontal magenta dashed lines correlate the insolation power range of the 880 -kyr climate anomaly (yellow vertical bar) with those of the hyetal cycles. Note that the astronomical precession minima correspond to climatic precession maxima. 


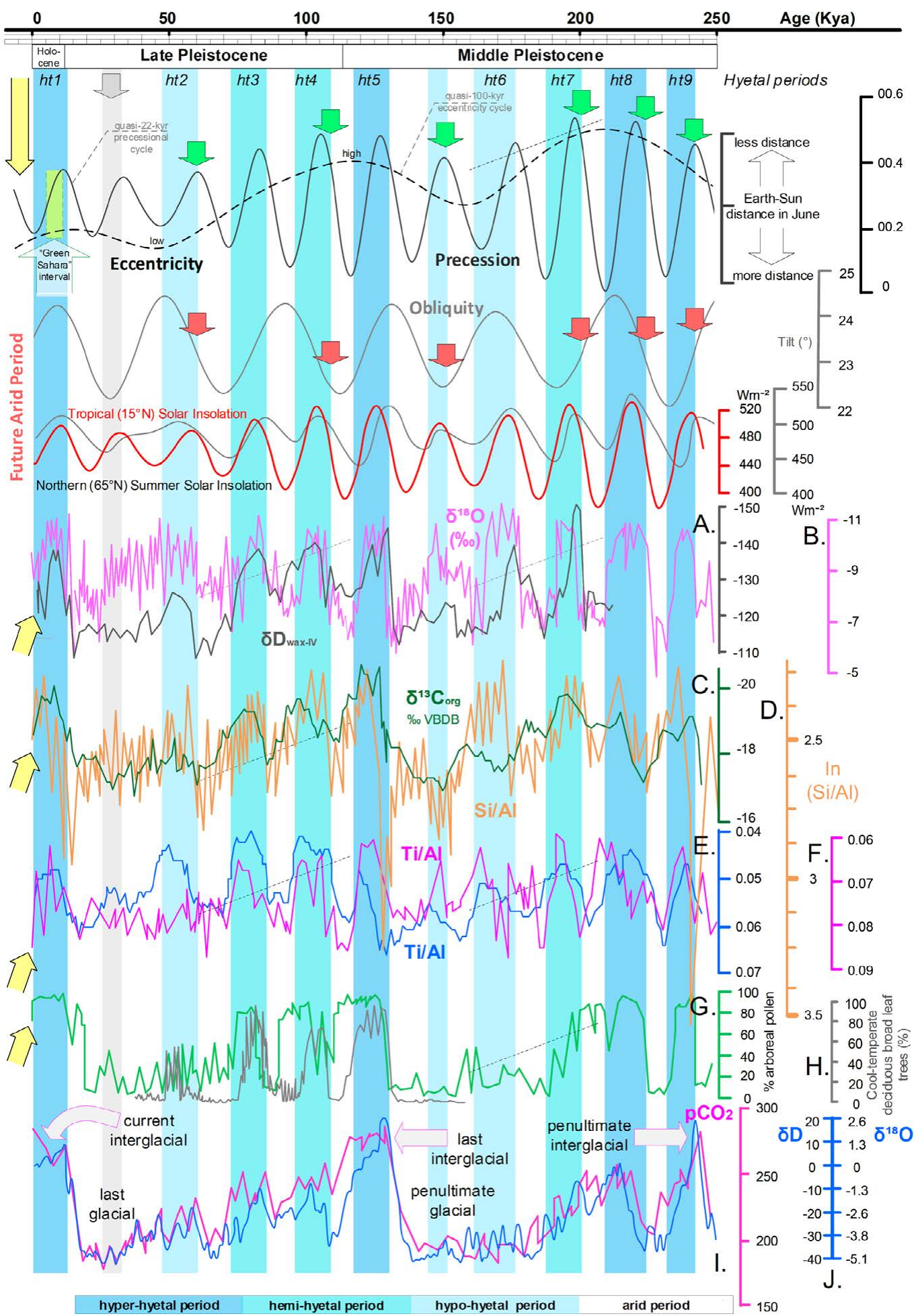

Figure 3: Comparison of the Earth's orbital parameters $[68,69]$ to hydroclimate proxies supporting the hyetal spectrum of the last 250 thousand years. A) Stable hydrogen isotopic composition of leaf waxes from the Gulf of Aden (core RC09-166) corrected for ice volume contributions [70]. B) Oxygen-isotopic composition of cave calcites ( $\delta^{18}$ Osp) from Chinese caves, a proxy of the Asian Monsoon intensity [71]. C) Organic carbon isotope record from the Niger deep-sea fan (core GeoB 4901) [18]. D) Log-ratio of silica to aluminium as a proxy of sediment opal content (ODP Site 658, subtropical North Atlantic [48]. E). Titanium/aluminium (Ti/Al) ratio of sediments from Niger deep-sea fans (core GeoB 4901) [18]. F) Ti/Al ratio of sediments from ODP Sites 967 and 968, eastern Mediterranean [17]. G) Continuous palynologic record, Tenagi Philipon, Greece [25]. H) Pollen composition of cool-temperate deciduous broad leaf trees from lake Nojiri, Japan [72]. I) Atmospheric CO2 record from EPICA Dome C core, Antarctica [73]. J) Stable isotope ratios of oxygen and hydrogen in the Vostok ice core record, Antarctica [74]. Green arrows show the onsets of hyetal events that apparently coincide with climatic precession maxima and obliquity minima (red arrows). Grey vertical bars highlight that even the weakest hypo-hyetal periods coincide with precession maxima: their low hydroclimatic intensity can be justified by the low eccentricity. The "Green Sahara" interval ( 11,000 to 5,000 years before present) [75], during which the area of the modern Sahara Desert received high amounts of rainfall, falls within the hyper-hyetal period $h t 1$; however, today we are crossing the $h t 1$ termination and entering into the subsequent arid period. Yellow arrows show the data indicating the current entry into an arid period. 


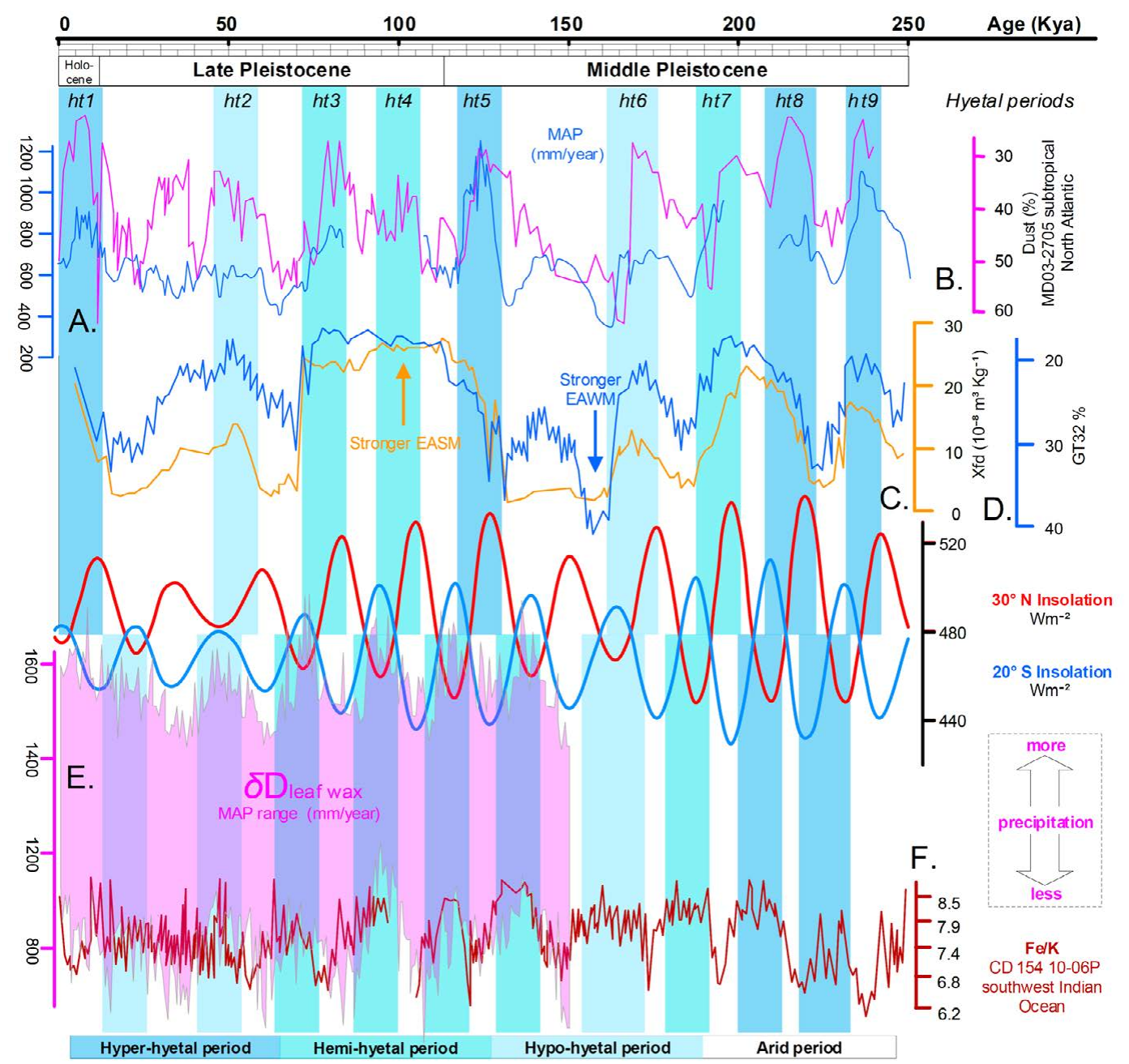

Figure 4: Correlation between the insolation variation and hydroclimatic proxies in the Northern and Southern Hemispheres. A) Meteoric ${ }^{10} \mathrm{Be}$ record from Pleistocene China as a proxy for monsoon palaeo-rainfall [21]. B) Saharan dust deposition across the subtropical North Atlantic recovered from the marine sediment core MD03-2705 [31] and considered to reflect the West African monsoon strength. C) Loess frequency-dependent magnetic susceptibility ( $x f d$ ), Luochuan, China [11]. D) Loess grain-size rate ( $>32 \mu \mathrm{m}$ particle content), Luochuan, China [11]. E) Hydrogen isotopic composition of sedimentary leaf waxes ( $\delta \mathrm{Dwax}$ ) from the Limpopo catchment, South Africa, as a proxy of the range in the mean annual precipitation [19]. $\delta \mathrm{D}$ values are reported in permille (\%) versus the Vienna Standard of Mean Ocean Water (VSMOW) standard. F) Continuous record of elemental ratios of Fe/K from the marine sediment core CD154-10$06 \mathrm{P}$, southwest Indian Ocean [23].

covariation. Among the well-established hydroclimatic proxies are the oxygen-isotopic composition in speleothems $\left(\delta^{18} \mathrm{O}_{\mathrm{sp}}\right)[9,10]$ and the loess-paleosol profiles $[10,11]$. Speleothems are inorganic carbonate deposits (mostly calcite and aragonite) that grow in caves and form from drip water that is supersaturated with $\mathrm{CaCO}_{3}$. Speleothems are highly suitable for radiometric dating using uranium-series disequilibrium techniques and can provide high temporal resolution ranging from a seasonal scale to a scale of $\sim 100$ years, depending on the sampling resolution. The $\delta^{18} \mathrm{O}_{\mathrm{sp}}$ records provide information that can be used to reconstruct past changes in precipitation and atmospheric circulation $[10,12]$. Here, a composite $\delta^{18} \mathrm{O}_{\mathrm{sp}}$ record from Chinese caves spanning the past $640 \mathrm{kyr}$ was used (Figure 1F) as proxy of the Asian Monsoon [11]. Loess is a deposit of wind-blown silt that blankets large areas of the continents. Loess accumulated during dry periods when dust fall was high and vegetation was predominantly short grasses. During episodes of warmer and wetter conditions, a reduction in loess deposition and in situ weathering of the loess already on the ground led to accretionary soil formation [10]. Today, the alternating sequence of loess units and paleosols forms the longest and most complete terrestrial record of Quaternary palaeoclimatic conditions on the continents. The magnetic susceptibility and grain size of loess are two well-accepted proxies of summer and winter monsoon climates, respectively $[10,13]$. Here, loess frequencydependent magnetic susceptibility $(x f d)$ (Figure $4 \mathrm{C}$ ) and loess grainsize data expressed as GT32 ( $>32 \mu \mathrm{m}$ particle content) (Figure 4D) from the Luochuan loess section, China, have been arrayed in Figure 4 as proxies of the warm/humid southerly East Asian summer monsoon and the dry/cold northerly East Asian winter monsoon, respectively [9]. Continuous archives of terrestrial lithogenic inputs such as concentrations of terrigenous elements ( $\mathrm{Fe}, \mathrm{K}, \mathrm{Al}, \mathrm{Si}, \mathrm{Mg}$, and $\mathrm{Ti}$ ) in marine sediments are considered to reflect wet versus dry conditions in the source areas. Moreover, elementary ratios such as the $\mathrm{Ti} / \mathrm{Al}$ ratio have been used to remove dilution effects of carbonate in order to clarify palaeohydroclimatic information [14-16]. Accordingly, the Ti/ $\mathrm{Al}$ ratio can also be considered a well-established palaeohydroclimatic proxy. A continuous Ti/Al record from the eastern Mediterranean 
[17] was arrayed in Figure 1N. In Figure 3E, the Mediterranean record is correlated with another $\mathrm{Ti} / \mathrm{Al}$ record from the Niger Delta [18]. The hydrogen isotopic composition of sedimentary leaf waxes $\left(\delta \mathrm{D}_{\text {wax }}\right)$ has been shown to primarily reflect precipitation $\left(\delta \mathrm{D}_{\mathrm{p}}\right)$ and is often taken to reflect the amount of precipitation [19]. The results of such a dataset from the Limpopo catchment, South Africa, were previously analysed [20] through a transient run with the isotopeenabled climate model iLOVECLIM and inferred to the arrayed graph of the mean annual precipitation range (Figure $4 \mathrm{E}$ ). ${ }^{10} \mathrm{Be}$ is a longlived cosmogenic radionuclide produced in the atmosphere, where it attaches to dust and then is deposited mainly through wet precipitation events. Hence, the ${ }^{10} \mathrm{Be}$ flux from the atmosphere is considered to be a proxy for rainfall (ref. [21] and references therein). Meteoric ${ }^{10} \mathrm{Be}$ preserved in Pleistocene Chinese loess has been used as a proxy for monsoon palaeo-rainfall [21]. In Figure 4A, such a graph was arrayed for comparison with the other hydroclimatic proxies. Among the not well-established palaeohydroclimatic proxies is the elementary $\mathrm{Fe} / \mathrm{K}$ ratio, which was recently considered as an alternative to the Ti/ $\mathrm{Al}$ ratio in marine sediments [22]. A continuous $\mathrm{Fe} / \mathrm{K}$ record from the Maldives Archipelago [22] was arrayed in Figure 1G. Another $\mathrm{Fe} / \mathrm{K}$ record from the southwest Indian Ocean [23] was arrayed in Figure 4F. Other potential hydroclimatic proxies include the organic carbon isotope records of sediments containing terrestrial vegetation material $\left(\delta^{13} \mathrm{C}_{\text {org-w }}\right)$ and, in a secondary role, the carbon isotope variation in marine carbonates $\left(\delta^{13} \mathrm{C}_{\text {carb }}\right)[24]$, the accumulation ratio of biogenic silica in freshwater lakes [10], the continuous arboreal palynologic records $[10,25]$, the dust and iron deposition records in marine sediments [26,27], and the records of atmospheric methane concentration [28]. The variation in the organic carbon isotope fractionation extracted from terrestrial vegetation $\left(\delta^{13} \mathrm{C}_{\text {org-w }}\right)$ has long been considered a good proxy of wet/arid climate modes (ref. [24] and references therein). Fossilised wood debris, often stored in near-shore marine sediments, are the best proxies of that variation, given that they provide sedimentary organic material that can safely be regarded as having originated from terrestrial vegetation. The extracted hydroclimatic information can be biased, however, because of the fact that marine-produced organic material is not influenced directly by hydroclimatic variation [24]. Biogenic silica records of lake sediments, such as the one of Lake Baikal (Figure $1 \mathrm{H}$ ), are considered proxies of diatom productivity $[10,29]$, which is sensitive to changes in the orbital parameters, although the specific climatic factor influencing the records is currently unknown [29]. Two such records, one terrestrial and one marine, were correlated in Figure 1 for comparison (Figure $1 \mathrm{H}$ and $1 \mathrm{~L}$ ). Wind-borne mineral aerosol ('dust') from marine sediments and ice cores carries considerable information about the aridification history of source areas and atmospheric circulation over different timescales [26]. Eolian dust fluxes in ice ages tend to be greater than those in interglacial periods. That phenomenon can be attributed to a strengthening of dust sources, together with a longer lifetime for atmospheric dust particles in the upper troposphere resulting from a reduced hydrological cycle [27]. Consequently, palaeo-dust records can be a good proxy of the past hydroclimate. In Figure 1O, a dust record derived from the analysis of marine sediments from ODP Site 1090, located in the Atlantic sector of the subantarctic zone [30], was arrayed for correlation together with another record from the marine sediment core MD03-2705 [31]. The latter is located directly adjacent to Ocean Drilling Program Site 659 and includes information of Saharan dust deposition across the subtropical North Atlantic that is considered to reflect the West African monsoon strength (ref. [31] and references therein).

Variation in palynologic records is also known to reflect climate variability [10]. The continuous 1.3 million-years arboreal pollen record from Tenagi Philipon, Makedonia, Greece [25], which is used here as the main proxy (Figure 1D), is expected to have been primarily influenced by palaeohydroclimatic variation rather than by palaeotemperature variation. That is because in palynologic analyses of other locations in Greece [32,33], the hydroclimate was shown to be the dominant factor influencing the vegetation distribution. The records of atmospheric methane $\left(\mathrm{CH}_{4}\right)$ concentration have been found to covary closely with the hydrological cycles $[34,35]$, suggesting the $\mathrm{CH} 4$ records to be very good hydroclimatic proxies. In Figure 1B, the 800,000 years atmospheric methane record from the EPICA Dome C ice core, Antarctica [36], was arrayed for correlation. All records were arrayed for correlation against their original timescales. All graphs are oriented so that wetter periods are represented by downward oscillations and drier periods are represented by upward oscillations. Hyetal and arid periods were defined on the basis of visual inspection of the graphs and the appearance of covariation among the proxies. Hyetal periods were defined by the occurrence of distinct downward peaks at least in three proxies, whereas arid periods were defined by the presence of zero to two peaks. The classification of the hyetal periods into categories of intensity was based on the amplifications of the oscillation peaks. Although the resulting hyetal spectrum is somewhat generalised, the resolution is satisfactory and in line with the purpose of the analysis. The separation of the hydroclimatic intensity into hyetal subcategories was done in order to cover a gap in the hydrological terminology by offering a term for the rainfall strength based not on the amount of rain water (precipitation) but on the amount of continental weathering caused by the rainfall. The concluded hyetal spectrum is thus mainly a contribution of proxies from weathering on land.

\section{Results}

Figure 1 shows how the best direct and indirect hydroclimatic proxies (see the Materials and Methods) correlate with the palaeotemperature and $\mathrm{CO} 2$ records of the last $1,200,000$ years. The covariation of hydroclimatic proxies converges to highlight 50 hyperhyetal, hemi-hyetal, hypo-hyetal, and arid periods characterised by high, semi-high, low, and very low levels of hydroclimatic intensity and continental weathering, respectively. The result is the synthesis of the spectrum of hydroclimatic intensity affecting Eurasia and tropical and northern Africa or, approximately, the Northern Hemisphere. In Figure 2 , that spectrum is compared to the Earth's orbital parameters. Figure 2 shows that hyper-hyetal periods and hypo-hyetal to arid periods largely coincide with the maxima and minima of the quasi-100-kyr eccentricity periods, respectively. Moreover, all of the hyetal periods start during high-insolation peaks, at the culminations of the eccentricitymodulated precession minima. Orbital precession minima correspond to times when the distance between the Earth and the Sun is smallest, 
resulting in higher insolation and maxima of another term, the climatic precession [37]. Climatic precession also depends on the Earth-Sun distance at the summer solstice. The highest-insolation hyper-hyetal periods occur when the solstice of boreal summer shifts towards the perihelion (e.g., as it was 10,000 years ago). Arid periods, in contrast, occur when the perihelion shifts towards the solstice of boreal winter (e.g., as it is today; see Figure 3). Obliquity plays only an auxiliary role in the configuration of the hyetal spectrum: it amplifies but never triggers hyetal periods. Indeed, there is no visible hyetal period corresponding to a high-insolation peak caused exclusively by an obliquity maximum, although there are plenty caused by climatic precession maxima (green circles in Figure 2). In addition, there are intermediate arid periods caused by precession minima, although they coincide with obliquity maxima (green arrows in Figure 2). As all hyetal periods correspond to insolation highs, this can be explained by the fact that even in the northern high $\left(>65^{\circ} \mathrm{N}\right)$ latitudes, where the effect of obliquity on insolation is stronger than that of precession [37], insolation peaks always correspond or are close to precession minima (see the bottom of Figure 2 and Figure 3, where higher resolution data are correlated). Precession minima (climatic precession maxima) correspond to hypohyetal and/or arid periods only during periods of eccentricity minima (grey arrows in Figure 2). The only exception to that rule occurs at $\sim 880$ kyr (marked by a yellow arrow and a yellow vertical bar in Figures 1 and 2), coinciding with an event that signalled, and probably caused, the onset of the 100-kyr glacial periodicity (see the Discussion). The correlation of the palaeotemperature proxy with the hyetal spectrum in Figure 1 suggests that lower and higher hyetal periods are closely related to glacial and interglacial cycles, respectively. Indeed, in Figure 3 (see also Figure 4 for the Southern Hemisphere), it can be seen that, within the quasi-100-kyr eccentricity cycles, quasi-22-kyr hyetal/arid cycles form ramps of descending hyetal amplitude (from hyper-hyetal to arid) following the eccentricity-modulated precession of the Earth's rotational axis [centred on a major cycle of $\sim 23,000$ years $(23,700$ and 22,400 years precisely) and a minor cycle of 19,000 years]. Both the $\mathrm{CO}_{2}$ records and the temperature records seem to be in good agreement with the hyetal cycles (Figure 3), suggesting a relationship that is closer than was previously thought.

\section{Discussion}

The relationship between variation in orbital precession and eccentricity and the Earth's hydroclimatic cycles is fundamental in cyclostratigraphy because of the stable 405-kyr period of the eccentricity over hundreds of millions of years [38]. Eccentricity by itself does not influence the variation of annual insolation, but it plays an important role in modulating the amplitude of the precessional cycles $[37,38]$. Accordingly, precession-driven hydroclimatic cycles have been traced in stratigraphical sequences of the Cenozoic $[39,40]$ and Mesozoic $[41,42]$. They have also been demonstrated in several climatic models [e.g. 43-45]. On the other hand, the combined influence of precession and obliquity has been found in the configuration of past hydroclimate systems such as that of Mediterranean [46] and the western Pacific Intertropical Convergence Zone [47] (see also Figure 5).

The correlations of the various palaeoclimatic records in the current study agree with previous results. Furthermore, they open a new window for observations into not only the Earth's climate history but also the nature of the records, which in one way or another seem to covary in the hyetal spectrum. Specifically, the close matching of the oscillations of well-established proxies of hydroclimatic intensity, such as the oxygen-isotopic composition of speleothems $\left(\delta^{18} \mathrm{O}_{\mathrm{sp}}\right)[9,10]$ and the loess-paleosol profiles $[10,11]$, and also those of indirect or not-well-established hydroclimatic proxies [e.g., the organic carbon isotope records of sediments containing terrestrial vegetation material $\left(\delta^{13} \mathrm{C}_{\text {org-w }}\right)$ [24], the elemental ratios of iron and potassium $(\mathrm{Fe} / \mathrm{K})$ in marine sediments [22], and the records of atmospheric methane concentration [28] (see the Materials and Methods) confirms both the hydroclimatic property of the proxies and the robustness of the concluded hyetal spectrum. In addition, it calls into question the natural processes that were previously inferred from some other records, such as those of the opal precipitation in the Atlantic coast of northwest Africa [48]. Specifically, the opal precipitation peaks during the glacial terminations have been considered to be evidence of deglacial loss of the North Atlantic intermediate water [48]; however, they are understood here as a proxy of hydroclimatic intensity (see Figure 1 and Figure 3). Accordingly, the opal precipitation peaks could be a result of multiple hyper-hyetal "Green Sahara" intervals [49] that caused strong weathering on the Sahara desert, increased riverine runoff, fertilisation of the sea (Saharan dust, rich in iron and phosphorus, fertilises Amazonia even today) [50], growth of diatom blooms, and biogenic opal precipitation through the demise phase of diatom blooms [51]. Indeed, more recent data showed that the ODP Site 658 from which the opal record originated [48] is located on the front of the estuary of the huge palaeoriver Tamanrasett, which had a giant drainage system in the western Sahara [52]. Hydroclimatic intensity and weathering are also suggested to be the previously unrecognised climate factor [29] responsible for diatom productivity in lake sediments such as those of Lake Baikal (Figure 1J). That would also explain why the sedimentary record of biogenic silica from the high-latitude $\left(51.5-56^{\circ} \mathrm{N}\right)$ Lake Baikal shows a surprisingly weak obliquity signal, with eccentricity and precessional frequencies dominating the record [10]. Likewise, the $\delta^{13} \mathrm{C}_{\text {org-w }}$ variation (Figure $1 \mathrm{O}$ and $1 \mathrm{P}$ ) should be seen as a direct hydroclimatic proxy containing information about mean annual precipitation [22]. In contrast, the carbon isotope records of marine carbonates $\left(\delta^{13} \mathrm{C}_{\text {carb }}\right)$ seem to contain indirect hydroclimatic information more closely related to continental weathering and carbon sequestration by terrestrial vegetation (Figure $1 \mathrm{~K}$ and $1 \mathrm{~L}$ ), as previously suggested [22]. The covariation between the temperature oscillations (a proxy of glacial/interglacial climatic cycles) and the hyetal cycles shown in Figure 1 is of particular interest concerning the nature of that relation and its driving mechanism. Is the concluded hyetal spectrum a result of the temperature variation among the glacial/interglacial cycles, or are the latter driven by the eccentricity-modulated precessional hyetal periods? Given that the exact mechanism causing the glacial/interglacial cycles is yet unclear [53], it does not seem unreasonable to ask that question, although today the current consensus is that the physical and biological processes of the oceans are the main climate feedback system responding to orbital oscillations [e.g. 53]. Indeed, the greater precipitation rates characterising the interglacial periods might be considered as a plausible consequence of the prevailing warmer temperatures in the 


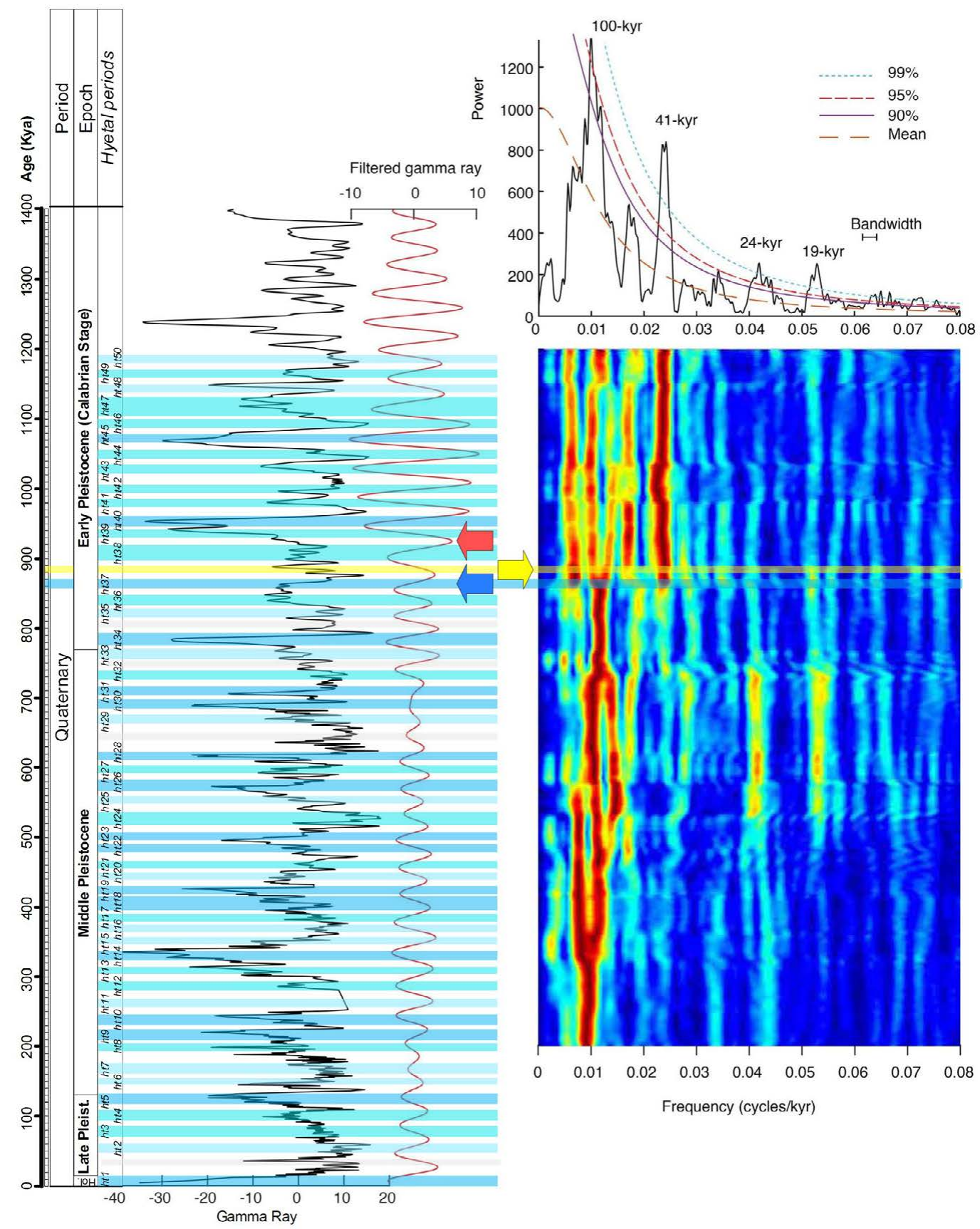

Figure 5: Correlation of the inferred hydroclimatic spectrum with the cyclostratigraphy of the original gamma ray series at ODP Site 1119, east of South Island, New Zealand (modified from ref. [76]: Supplementary Figure 4 with permission). Left: Original gamma ray series from ref. [64]. The original age model [64] has been fine-tuned on the basis of the filtered 40.9-kyr obliquity cycles (Gaussian filter, red line) [76]. Right: $2 \pi$ power spectrum and evolutionary spectrograms for inspecting stratigraphic frequencies and patterns of the gamma ray series (see methodology in ref. [76]). Notice that all hyper-hyetal periods correspond to gamma ray peaks apart from the ht37 (blue arrow), which follows the 880-Kyr anomaly (yellow arrow and yellow horizontal bar). Although the domination of the 41-kyr obliquity-related cycles seems to have declined since $~ 930 \mathrm{kyr}$ (red arrow), the transition from $41-\mathrm{kyr}$ obliquity-related cycles to quasi-100-kyr eccentricity-related cycles seems to have been completed at $\sim 870 \mathrm{kyr}$, succeeding the 880 -kyr anomaly.

biosphere. As such, interglacial precipitation rates would increase with a rate of approximately $2 \%$ per degree of surface warming as a result of an increase in the radiative flux divergence of the atmosphere at a rate of $2 \%$ per K [54]. In that way, the change of the global mean annual precipitation would be a slow procedure depending on and following the glacial/interglacial biosphere temperature variation. However, the magnitude of the intense, convectively generated precipitation develops independently of those conditions and increases following the Clausius-Clapeyron law at the same rate as the column moisture, that is, a $\sim 7 \%$ increase in specific humidity per $\mathrm{K}$ of surface warming [54]. Thus, even with cold glacial mean annual temperatures, strong midday insolation on land (Figure 6) could cause Violent Hydroclimate Perturbation (VHP) and intensified hyetal phenomena, such as the heavy convective rainfalls observed on tropical islands just after the hottest time of day [55].

Therefore, during the periods of climatic precession maxima, high insolation could maximise the hydroclimatic intensity driven directly 

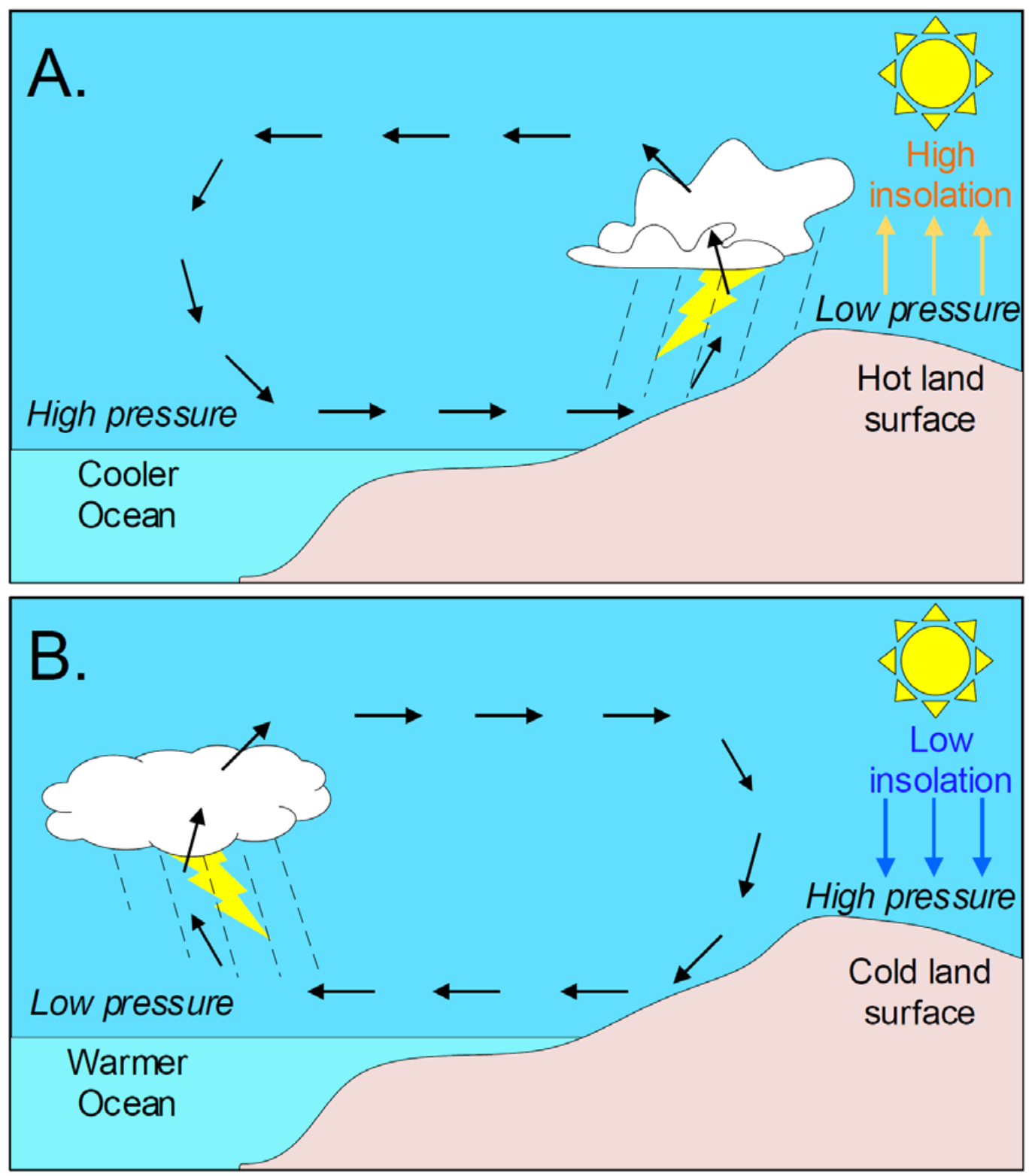

Figure 6: Simplified schematic explanation of the strong influence of insolation on the creation of convective rainfalls. Increased insolation drives an enhanced land-ocean thermal gradient and moisture convergence over land that strengthens and forces the monsoon to bring rainfall deep into inland areas (A). In contrast, weak insolation moves the cold continental wind masses toward the ocean, keeping the inland arid (B).

by the daily incoming solar radiation and independently of the prevailing mean annual temperatures in the biosphere. Conclusively, it is suggested here as a working hypothesis for future climate simulation models that the missing link coupling the Earth's orbital and climate histories might be the directly orbitally forced hydroclimatic intensity. Indeed, given that the glacial/interglacial biosphere temperature is driven by atmospheric $\mathrm{CO}_{2}$ variation, it is worth noting that the Antarctic records of $\mathrm{CO}_{2}$ and $\mathrm{CH}_{4}$ concentrations covary [56] in precessional pace [36]. In addition, $\mathrm{CH}_{4}$ sources have been found that originated in tropical wetlands and seasonally inundated floodplains [57,58], which are known to have been dominated by a precessiondriven hydroclimate. On the other hand, the essential contribution of the huge quantities of carbon stored in high-latitude permafrost regions [59] would prove to be more critical in deglaciation only after it was demonstrated that convective hyetal phenomena developed in the Arctic during climatic precession maxima. Such intensified hyetal phenomena might have led to quicker permafrost thawing and carbon release into the atmosphere [60], which otherwise are slow processes that would follow and not precede deglaciation [57]. In addition to the questions about the cause of Pleistocene glaciation, conclusions can be inferred from the hyetal spectrum regarding the mechanism controlling the periodicity of the glacial-interglacial cycles during the last $\sim 900,000$ years. The age of $900 \mathrm{kyr}$ (MIS 22) is a threshold in the Pleistocene glaciation because it marks the currently not well understood passing from 41-kyr obliquity-related glacial cycles to quasi-100-kyr eccentricity-related glacial cycles [2,6,7]. That " $900-\mathrm{kyr}$ event" [61,62] signals the first long glacial period of the Pleistocene and is characterised by extremely low sea surface temperatures (SSTs) in the North Atlantic and tropical-ocean upwelling regions, increased aridity in Africa and Asia, a $\delta^{13} \mathrm{C}_{\text {carb }}$ minimum (see Figure 
1L), sustained decreased carbonate in the subtropical south Atlantic, northward migration of the Antarctic Polar Front, and major change in the deep-water circulation of the oceans [61,62]. The 900-kyr event is believed to have possibly started as early as the MIS24 ( 940,000 years ago; see Figure $1 \mathrm{E}$ and Figure 5) and was due to orbital changes resulting in minima in the insolation amplitude [7,61,62]. A thorough observation of the hyetal spectrum reveals, however, that the main arid period characterising the 900 -kyr event is the only arid period of the hyetal spectrum that falls within a high-insolation interval of both high eccentricity and high climatic precession; in other words, a period that should have resulted in a hyetal period rather than an arid period. That anomaly, dated at $\sim 880,000$ years ago (yellow vertical bars in Figures 1 and 2), perfectly coincides with the exact time of transition to the quasi-100-kyr glacial periodicity (see the spectral analysis in Figure 5). Therefore, the 900-kyr event is not a result of any change in insolation. Instead, it should be considered as a currently unexplained feedback perturbation of the Earth's internal climate system (e.g., a permanent change in the circulation of ocean currents that resulted in large-scale changes in atmospheric circulation).

\section{Declaration of Competing Interest}

The author declares no competing interests.

\section{Acknowledgments and Funding Sources}

This research was not funded by public, commercial, or not-forprofit grants.

\section{References}

1. Ogg JG, Ogg GM, Gradstein FMA (2016) coincise geological timescale (Elsevier, Amsterdam, 2016)

2. Hays JD, Imbrie J, Shackleton NJ (1976) Variations in the Earth's orbit pacemaker of the ice ages. Science 194: 1121-1132.

3. Paillard D (2015) Quaternary glaciations: From observations to theories. Quaternary Science Reviews 107:11-24.

4. Hodell DA, Channell, JET (2016) Mode transitions in Northern Hemisphere glaciation: Co-evolution of millennial and orbital variability in Quaternary climate. Climate of the Past 12: 1805-1828.

5. Maslin MA, Ridgwell AJ (2005) Mid-Pleistocene revolution and the 'eccentricity myth. Geological Society, London, Special Publications 247: 19-34.

6. Lisiecki LE, Raymo MEA (2005) Pliocene-Pleistocene stack of 57 globally distributed benthic $\mathrm{d} 18 \mathrm{O}$ records. Paleoceanography 20.

7. Maslin MA, Brierley CM (2015) The role of orbital forcing in the early middle Pleistocene transition. Quaternary International 389: 47-55.

8. Raymo ME, Huybers P (2008) Unlocking the mysteries of the ice ages. Nature 451: 284-285.

9. Hai Cheng, R. Lawrence Edwards, Ashish Sinha, Christoph Spötl, Liang Yi, et al. (2016) The Asian monsoon over the past 640,000 years and ice age terminations. Nature 534: 640-646.

10. Bradley RS (2014) Paleoclimatology: Reconstructing climates of the Quaternary (3rd edn. Academic Press/Elsevier, Amsterdam,

11. Qingzhen Hao, Luo Wang, Frank Oldfield, Shuzhen Peng, Li Qin, et al. (2012) Delayed build-up of Arctic ice sheets during 400,000-year minima in insolation variability. Nature 490: 393-396.

12. Caley T, Roche DM, Renssen H (2014) Orbital Asian summer monsoon dynamics revealed using an isotope-enabled global climate model. Nature Communication 5.

13. LinZeng, ShuangwenYi, WenfangZhang, HanFeng, Anqi Lv, et al. (2020) Provenance of loess deposits and stepwise expansion of the desert environment in NE China since 1.2 Ma: Evidence from Nd-Sr isotopic composition and grain-size record. Global and Planetary Change 185

14. Boyle EA (1983) Chemical accumulation variations under the Peru Current during the past 130,000 years. Journal of Geophysical Research 88: 7667-7680.

15. Shimmield G, Mowbray SR (1991) The inorganic geochemical record of the northwest Arabian Sea: A history of productivity variation over the last 400 k.y. from sites 722 and 724. Proceedings of the Ocean Drilling Program, Scientific Results 117: 409-429.

16. Holtvoeth J, Kolonic S, Wagner T (2005) Soil organic matter as an important contributor to Late Quaternary sediments of the tropical West African continental margin. Geochimica et Cosmochimica Acta 69: 2031-2041.

17. Konijnendijk TYM, Ziegler M, Lourens LJ (2015) On the timing and forcing mechanisms of late Pleistocene glacial terminations: Insights from a new highresolution benthic stable oxygen isotope record of the eastern Mediterranean Quaternary Science Reviews 129: 308-320.

18. MatthiasZabelRalph RSchneiderThomasWagnerAdesina TAdegbieUwede Vries, et al. (2001) Late Quaternary climate changes in central Africa as inferred from terrigenous input to the Niger fan. Quaternary Research 56: 207-217.

19. Dirk Sachse, Isabelle Billault, Gabriel J. Bowen, Yoshito Chikaraishi, Todd E. Dawson, et al. (2012) Molecular paleohydrology: Interpreting the hydrogen-isotopic composition of lipid biomarkers from photosynthesizing organisms. Annual Review of Earth and Planetary Sciences 40: 221-249.

20. Caley, Thibaut; Jimenez-Espejo, Francisco J; García-Comas, Carmen, et al. (2018) A two-million-year-long hydroclimatic context for hominin evolution in southeastern Africa. Nature 560: 76-79.

21. J Warren Beck, Weijian Zhou, Cheng Li, Zhenkun Wu, et al. (2018) A 550,000-year record of East Asian monsoon rainfall from ${ }^{10} \mathrm{Be}$ in loess. Science 360: 877-881.

22. Tereza Kunkelova, Simon JA Jung, Erica S de Leau, Nick Odling, Alex L Thomas, et al. (2018) A two million year record of low-latitude aridity linked to continental weathering from the Maldives. Progress in Earth and Planetary Science 5.

23. Margit H. Simon, Martin Ziegler, Joyce Bosmans, Stephen Barker, Chris J.C. Reason, et al. (2015) Eastern South African hydroclimate over the past 270,000 years. Scientific Reports 5.

24. Brikiatis L (2019) Arido-eustasy: A new example of non-glacial eustatic sea level change. Gondwana Research 70: 25-35.

25. Tzedakis PC, Hooghiemstra H, Pälike H (2006) The last 1.35 million years at Tenaghi Philippon: Revised chronostratigraphy and long-term vegetation trends. Quaternary Science Reviews 25: 3416-3430.

26. BA Maher, JM Prospero, D Mackiec, D Gaierod, PP Hesse, et al. (2010) Global connections between aeolian dust, climate and ocean biogeochemistry at the present day and at the last glacial maximum. Earth-Science Reviews 99: 61-97.

27. Lambert, B Delmonte, JR Petit, M Bigler, PR Kaufmann, et al. (2008) Dust-climate couplings over the past 800,000 years from the EPICA dome C ice core. Nature 452 : 616-619.

28. Michael Bock, Jochen Schmitt, Jonas Beck, Barbara Seth, Jérôme Chappellaz, et al. (2017) Glacial/interglacial wetland, biomass burning, and geologic methane emissions constrained by dual stable isotopic $\mathrm{CH} 4$ ice core records. PNAS 114: E5778-E5786.

29. Mackay AW, Edlund MB, Khursevich G (2010) Diatoms in ancient Lakes in The diatoms: Applications for the Environmental and Earth Sciences (edsb: Smol, J. P. \& Stoermer, E. F.) pg: 209-228 (2nd edn, Cambridge University Press).

30. Alfredo Martínez-Garcia, Antoni Rosell-Melé, Samuel L. Jaccard, Walter Geibert, Daniel M. Sigman, et al. (2011) Southern Ocean dust-climate coupling over the past four million years. Nature 476: 312-315.

31. C Skonieczny, D McGee, G Winckler3, A. Bory3, LI Bradtmille, et al. (2019) Monsoon-driven Saharan dust variability over the past 240,000 years. Science Advance 5.

32. Tzedakis PC, Lawson IT, Frogley MR, Hewitt GM, Preece RC (2002) Buffered tree population changes in a quaternary refugium: Evolutionary implications. Science 297: 2044-2047.

33. Lawsona I, Frogley M, Bryant C, Preece R, Tzedakis P (2004) The Lateglacial and Holocene environmental history of the Ioannina basin, north-west Greece. Quaternary Science Reviews 23: 1599-1625. 
34. Tzedakis PC, Pälike H, Roucoux KH, de Abreu L (2009) Atmospheric methane, southern European vegetation and low-mid latitude links on orbital and millennial timescales. Earth and Planetary Science Letters 277: 307-317.

35. Konijnendijk TYM, Weber SL, Tuenter E, van Weele M (2011) Methane variations on orbital timescales: A transient modeling experiment. Climate of the Past 7: 47-77.

36. Laetitia Loulergue, Adrian Schilt, Renato Spahni, Valérie Masson-Delmotte, Thomas Blunier, et al. (2008). Orbital and millennial-scale features of atmospheric $\mathrm{CH} 4$ over the past 800,000 years. Nature 453: 383-386.

37. Berger A (1978) Long-term variations of caloric insolation resulting from the earth's orbital elements. Quaternary Research 9: 139-167.

38. Hinnov LA (2014) Cyclostratigraphy and its revolutionizing applications in the earth and planetary sciences. GSA Bulletin 125: 1703-1734.

39. Röhl U, Bralower TJ, Norris RD, Wefer G (2000) New chronology for the late Paleocene thermal maximum and its environmental implications. Geology 28: 927-930.

40. De Menocal PB (1995) Plio-Pleistocene African climate. Science 270: 53-59.

41. SK Hüsing, A Beniest, A van der Boon, HA Abels, MHL Deenen, et al. (2014) Astronomically-calibrated magnetostratigraphy of the Lower Jurassic marine successions at St. Audrie's Bay and East Quantoxhead (Hettangian-Sinemurian; Somerset, UK). Palaeogeography Palaeoclimatology Palaeoecology 403: 43-56.

42. Jingeng Sha, Paul E. Olsen, Yanhong Pan, Daoyi Xu, Yaqiang Wang, et al. (2015) Triassic-Jurassic climate in continental high-latitude Asia was dominated by obliquity-paced variations (Junggar Basin, Ürümqi, China). PNAS 112: 3624-3629.

43. Kutzbach JE (1981). Monsoon climate of the early Holocene: Climate experiment with the earth's orbital parameters for 9000 years ago. Science 214: 59-61.

44. A Marzocchi, DJ Lunt, R Flecker, CD Bradshaw, A. Farnsworth, et al. (2015) Orbital control on late Miocene climate and the North African monsoon: Insight from an ensemble of sub-precessional simulations. Climate of the Past 11: 1271-1295.

45. Jalihal C, Bosmans JHC, Srinivasan J, Chakraborty A (2019) The response of tropical precipitation to Earth's precession: The role of energy fluxes and vertical stability. Climate of the Past 15: 449-462.

46. StefanKlotz, SéverineFauquette, NathalieCombourieu-Nebout, DieterUhl, Jean-Pierre Suc, et al. (2006) Seasonality intensification and long-term winter cooling as a part of the Late Pliocene climate development. Earth and Planetary Science Letters 241: 174-187.

47. Yi Liu, Li Lo, Zhengguo Shi, Kuo-Yen Wei, Chien-Ju Chou, et al. (2015) Obliquity pacing of the western Pacific Intertropical Convergence Zone over the past 282,000 years. Nature Communications 6.

48. AN Meckler, DM Sigman, KA Gibson, R François, A Martínez-García, et al. (2013) Deglacial pulses of deep-ocean silicate into the subtropical North Atlantic Ocean. Nature 495: 495-498.

49. Isla S. Castañeda, Stefan Mulitza, Enno Schefuß, Raquel A. Lopes dos Santos, Jaap S. Sinning, et al. (2009) PNAS 106: 20159-20163.

50. Bristow CS, Hudson-Edwards KA, Chappell A (2010) Fertilizing the Amazon and equatorial Atlantic with West African dust. Geophysical Research Letter 37.

51. Smetacek VS (1985) Role of sinking in diatom life-history cycles: Ecological, evolutionary and geological significance. Marine Biology 84: 239-251.

52. C Skonieczny, P Paillou, A Bory, G Bayon, L Biscara, et al. (2015) African humid periods triggered the reactivation of a large river system in Western Sahara. Nature Communications 6 .

53. Kohfeld KE, Ridgwell A (2009) Glacial-interglacial variability in atmospheric CO2 in Surface Ocean/Lower Atmosphere Processes (Eds: Le Quéré, C. \& Saltzman, E.) (Geophysical Monograph Series 37, American Geophysical Union, Washington).

54. Igel MR, Biello JA (2019) A reconstructed total precipitation framework. Climate and Atmospheric Science 2.

55. Cronin TW, Emanuel KA, Molnar P (2014) Island precipitation enhancement and the diurnal cycle in radiative-convective equilibrium. Q J Royal Meteorological Society 141: 1017-1034.
56. Past Interglacials Working Group of PAGES (2016) Interglacials of the last 800,000 years. Reviews of Geophysics 54: 162-219.

57. Michael Bock, Jochen Schmitt, Jonas Beck, Barbara Seth, Jérôme Chappellaz, et al. (2017) Glacial/interglacial wetland, biomass burning, and geologic methane emissions constrained by dual stable isotopic CH4 ice core records. PNAS 114: E5778-E5786.

58. Eric Monnin, Andreas Indermühle, André Dällenbach, Jacqueline Flückiger, Bernhard Stauffer, et al. (2001) Atmospheric CO2 concentrations over the Last Glacial Termination. Science 291: 112-114.

59. K A Crichton, N Bouttes, DM Roche, J Chappellaz, G. Krinner, et al. (2016) Permafrost carbon as a missing link to explain $\mathrm{CO}_{2}$ changes during the last deglaciation. Nature Geoscience 9: 683-686.

60. Rebecca B. Neumann, Colby J. Moorberg, Jessica D. Lundquist, Jesse C. Turner, Mark P. Waldrop, et al. (2019) Warming effects of spring rainfall increase methane emissions from thawing permafrost. Geophysical Research Letter 46: 1393-1401.

61. Peter U Clark, David Arche, David Pollard, Joel D.Blum, Jose A Rial, et al. (2006) The middle Pleistocene transition: Characteristics. mechanisms, and implications for long-term changes in atmospheric PCO2. Quaternary Science Reviews 25: 3150-3184.

62. Kemp AES, Grigorov I, Pearce RB, Naveira Garabato AC (2010) Migration of the Antarctic Polar Front through the mid-Pleistocene transition: Evidence and climatic implications. Quaternary Science Reviews 29: 1993-2009.

63. Wagner B, Vogel H, Francke A (2019) Mediterranean winter rainfall in phase with African monsoons during the past 1.36 million years. Nature 573: 256-260.

64. Carter RM, Gammon P (2004) New Zealand maritime glaciation: Millennial-scale southern climate change since 3.9 Ma. Science 304: 1659-1662.

65. Lisiecki LE (2010) A simple mixing explanation for late Pleistocene changes in the Pacific-South Atlantic benthic $\delta^{13} \mathrm{C}$ gradient. Climate of the Past 6: 305-314.

66. Hoogakker BAA, Rohling E.J, Palmer MR, Tyrrell T, Rothwell RG (2006) Underlying causes for long-term global ocean delta C-13 fluctuations over the last $1.20 \mathrm{Myr}$. Earth and Planetary Science Letters 248: 15-29.

67. Jahn B, Schneider RR, Müller PJ, Donner B, Röhl U (2005) Response of tropical African and East Atlantic climates to orbital forcing over the last 1.7 Ma. Geological Society, London, Special Publications 247: 65-84.

68. J Laskar, P Robutel, F Joutel, M. Gastineau, ACM Correia, B. Levrard et al. (2004) A long-term numerical solution for the insolation quantities of the Earth. Astronomy and Astrophysics 428.

69. Laskar, J., Fienga, A., Gastineau, M. \& Manche, H., 2011. La2010: A new orbital solution for the long-term motion of the Earth. Astronomy and Astrophysics 532, A89. http://dx.doi.org/10.1051/0004-6361/201116836

70. Tierney JE, de Menocal PB, Zander PD (2017) A climatic context for the out-ofAfrica migration. Geology 45: 1023-1026.

71. Hai Cheng, R Lawrence Edwards, Wallace S Broecker, George H Denton, Xinggong Kong, et al. (2009) Ice age terminations. Science 326: 248-252.

72. Kumon F, Tawara T (2009) Detailed reconstruction of paleoclimate based on total organic carbon proxy of lake sediment during the past $160 \mathrm{ka}$ in central Japan. The Journal of the Geological Society of Japan 115: 344-356.

73. Dieter Lüthi, Martine Le Floch, Bernhard Bereiter, Thomas Blunier, Jean-Marc Barnola, et al. (2008) High-resolution carbon dioxide concentration record 650,000800,000 years before present. Nature 453: 379-382

74. Sime LC, Wolff EW, Oliver KIC, Tindall JC (2009) Evidence for warmer interglacials in East Antarctic ice cores. Nature 462: 342-345.

75. Tierney JE, Pausata FSR, de Menocal, Peter B (2017) Rainfall regimes of the Green Sahara. Science Advance 3

76. Li M, Hinnov LA, Huang C, Ogg JG (2018) Sedimentary noise and sea levels linked to land-ocean water exchange and obliquity forcing. Nature Communications 9.

\section{Citation:}

Brikiatis L (2021) Astronomical Control of the Hydroclimate During the Past 1.2 Million Years. Geol Earth Mar Sci Volume 3(2): 1-11. 